\section{The intuitive nurse in critical care practice: a phenomenolog- ical study}

\author{
Parkhide Hassani, ${ }^{1}$ Alireza Abdi, ${ }^{1}$ \\ Rostam Jalali, ${ }^{2}$ Nader Salari' ${ }^{2}$ \\ 'Faculty of Nursing and Midwifery, \\ Shahid Beheshti University of Medical \\ Sciences, Tehran; ${ }^{2}$ Faculty of Nursing and \\ Midwifery, Kermanshah University of \\ Medical Sciences, Kermanshah, Iran
}

\section{Abstract}

Intuition in clinical practice is the ability to experience the elements of a clinical situation as a whole, and to solve a problem or reach a decision with limited concrete information. Benner theorized that the expert nurse acts on intuition, but that he/she also deals with some ambiguities. However, there is a lack of studies about intuitive nursing in the critical care arena, where more critically ill patients are admitted. So, this study was conducted to explore the features of the intuitive nurse in critical care practice. In a descriptive-phenomenological study, twelve nurses employed in critical care units of the hospitals affiliated to Kermanshah University of Medical Sciences were recruited to the study, as purposive, a semi-structured interview was administered to them, then written down verbatim. The data was managed by MAXQDA 10 software (VERBI $\mathrm{GmbH}$, Berlin, Germany) and analyzed as qualitative through the seven-stage approach of Colaizzi. Of the 12 nurses who participated in the study, seven (58.3\%) were female and married, $88.3 \%$ (10 people) had a Bachelor of Nursing and the mean and standard deviations of the participants' age, job experience and critical care experience were $36.66 \pm 7.01$, $13.75 \pm 6.82$ and $7.66 \pm 3.36$ years, respectively. From the qualitative analysis of the data, we extracted three main themes, including proficiency, connection and benevolence, and ten sub-themes. The intuitive nurses were substantially proficient in terms of knowledge, skill and experience, and relationships to patients. They desired to help the patients based on their consciences.

\section{Introduction}

Intuition was first included in the nursing discipline during the 1970 s, simultaneous to the analysis of abstract constructs in nursing by qualitative approaches. ${ }^{1}$ The concept was considered a gestalt experience of awareness, without a logical explanation, ${ }^{2}$ and was defined as a feeling of knowing that something terrible is happening, ${ }^{3}$ an immediate unconsciousness perception, ${ }^{4}$ a direct understanding a truth without the analytical process, ${ }^{5}$ a non-linear process of knowing through physical awareness, emotional awareness and making connections between them, ${ }^{6}$ and an irrational unconsciousness approach of knowing. Intuition in nursing is comprehended as a gut feeling and many negative senses such as having a very bad feeling, feeling uncomfortable, feeling there was something terribly wrong, something missing or there was something they had not done. ${ }^{4,7}$

Intuition is regarded as the ability to experience the elements of a clinical situation as a whole, to solve a problem or reach a decision with limited concrete information. ${ }^{8}$ Furthermore, intuition is considered as the art of nursing, aesthetic knowing, and tacit knowledge ${ }^{9,10}$ Green asserted that understanding of the nature and development of intuition in nursing can help nurse educators foster it in young nurses, and give clinicians more confidence in this aspect of their knowledge, allowing them to respond to their intuitions with greater assurance. ${ }^{11}$ Benner theorized five steps necessary to reach clinical competency in nursing; these stages commenced with novice and continued to expert, where expert nurses are not consciously aware of their practice because it has become part of their being. There is a deep involvement in their environment and they simply experience a situation and respond in a fluid, automatic manner. They understand clinical situations through intuition. ${ }^{12-14}$ However, Cork (2014) found two problems with the verification of Benner's theory, including difficulties about assessing and measuring the abstract concepts of the theory, and inadequate information about intuition in expert nurses. ${ }^{15}$

Various studies have been made of intuition in nursing, but there are only a few research reports about the intuitive nurse. Some concluded that intuitive nurses make a holistic judgment in clinical settings, and integrate diverse information to make a decision. ${ }^{16}$ Miller argued these nurses were willing to act on their intuitions, were skilled clinicians, incorporating a spiritual component into their practices, expressed an interest in the abstract nature of things, and were risk takers. ${ }^{2}$ It is also believed that critical care nurses use intuition as best practice in complicated and emergency clinical situations, ${ }^{17}$ because they care for more critically ill patients. ${ }^{18,19}$ Given that intuition is a complex, mysterious, and abstract concept, which cannot be articulated by nurses in clinical settings,${ }^{20}$ the idea of incorporating it in the nursing curriculum faces many restraints. ${ }^{21}$ Therefore, the current study has been conducted to explore the fea-
Correspondence: Alireza Abdi, Faculty of Nursing and Midwifery, Shahid Beheshti University of Medical Sciences, postal code: 6718997583, Tehran, Iran (International branch).

Tel.: 989183370389.

E-mail: A_abdi61@yahoo.com

Key words: Intuition; nurses; critical care; qualitative research.

Acknowledgments: this study was taken from a $\mathrm{PhD}$ dissertation of nursing approved by Shahid Beheshti University of Medical Sciences (SBMU). We are grateful for all officials of nursing and midwifery school of SBMU, research deputy and affiliated hospitals of KUMS, as well as, the nurses who participated to the study.

Contributions: PH contributed in designing the research, assessment and writing the paper. $\mathrm{AA}$ collected the data, performed the interviews, contributed in designing the project and writing the paper. RJ reviewed all the interviews and consulted all the process of the research in term of designing to writing the manuscript. NS contributed in the designing the project.

Conflict of interests: the authors declare no potential conflict of interests.

Received for publication: 3 December 2015.

Revision received: 27 January 2016.

Accepted for publication: 27 January 2016 .

This work is licensed under a Creative Commons Attribution NonCommercial 3.0 License (CC BYNC 3.0).

(C) Copyright P. Hassani et al., 2016

Licensee PAGEPress, Italy

Nursing Reports 2016; 6:

doi:10.4081/nursrep.2016.5665

tures of the intuitive nurse in critical care practice.

\section{Materials and Methods}

\section{Design}

This qualitative study was done as descriptive-phenomenology. Phenomenology is used to investigate the lived experiences of humans, as established by Edmund Husserl in the early twentieth century. ${ }^{22}$ Although the origins of phenomenology can be traced back to Kant and Hegel, Vandenberg regards Husserl as the fountainhead of phenomenology in the twentieth century. Husserl rejected the belief that objects in the external world exist independently and that the information about objects is reliable. He argued that people can be certain about how things appear in, or present themselves to, their consciousness. To arrive at certainty, anything outside immedi- 
ate experience must be ignored, and in this way the external world is reduced to the contents of personal consciousness. Realities are thus treated as pure phenomena and the only absolute data from where to begin. Husserl named his philosophical method phenomenology, the science of pure phenomena. ${ }^{23}$ The phenomenology categorizes into two approaches; interpretive and descriptive, interpretative method focuses on lived experience of participants by incorporating phenomenology and interpretation. The aims are the analysis of elements of the reflective personal and subjective view of individual experiences and attempts to report on the participant's experience by considering the researchers own view of the world. It recognizes the researcher within the research and analytic process. Indeed, Interpretations are based on the researcher's own conceptions, beliefs, expectations, and experiences. ${ }^{24}$ The purpose of the descriptive approach is to assess the experiences of individuals as understood by them without interference from the researchers in the interpretation of the meanings. In this case, the researchers must bracket all their prior knowledge about the issue..$^{22}$ Bracketing in descriptive phenomenology is a means of demonstrating the validity of the data collection and analysis process. Therefore, efforts should be made by researchers to put aside their repertoires of knowledge, beliefs, values and experiences in order to accurately describe participants' life experiences. $^{25}$ Because the descriptive phenomenology used to reach true meanings through engaging in-depth into reality, ${ }^{26}$ and intuition is an abstract concept that cannot be studied objectively, therefore, to investigate its essence, we referred to the experiences of those who have used it by this approach. ${ }^{3}$

\section{Participants}

The participants were twelve purposely recruited nurses employed in critical care units of the hospitals affiliated to Kermanshah University of Medical Science (KUMS), they were varied in term of sex, age, work experience and critical care experience. The notion of critical care units is regarded to Intensive Care Units (ICUs) and Cardiac Care Units (CCUs), where designed to care for critically ill patients in a threatening condition and equipped by advanced monitoring and resuscitation devices. The skillfully, expert personnel who are qualified to response to emergency circumstances, tasked to take care of the patients. Other studied also referred to ICU and CCU as the critical care units. ${ }^{27,28}$ The participants were enlisted from the five hospitals of Imam Reza, Imam Ali, Farabi, Taleghani, and Imam Khomaini, where were selected from 19 governmental centers affiliated to KUMS, and admitted critical care patients in
ICUs and CCUs. The purposeful sampling in qualitative researches is directed to discover who has a rich experiences about the target phenomenon, ${ }^{29}$ which used in our study. The inclusion criteria consisted of working in critical care units for at least three years, having experience of intuition in clinical practice, and consent to participate in the study. Nurses who were reluctant to enroll in the study or had no experience of intuition, and could not remember any, were excluded from the study.

The sample size was according to data saturation with no appearance of new data during the interviews. Saturation is a tool used for ensuring that adequate and quality data are collected to support the study. Saturation is frequently reported in qualitative research and may be the gold standard. ${ }^{30}$ Even the variety of saturation level in different studies, ${ }^{31,32}$ some indicated that the Saturation during data gathering and analysis in qualitative studies happens when, under the scrutiny of at least two experts in qualitative research, no new information is obtained..$^{33}$ In our study saturation occurred during interview 10, after which we carried out two additional interviews for assurance.

\section{Ethical consideration}

The permission was taken from the officials of the research deputy of Shahid Beheshti University of Medical Sciences (SBMU), KUMS and the hospitals affiliated to KUMS. The research approved by the ethics committee of SBMU. The topic and objectives of the study were clearly explained to the participants, assurance to confidentiality and anonymity of personal information were given, and finally the written informed consent were taken from them.

\section{Data collection}

For data collection, after taking the necessary permissions, the researcher referred to the critical care units of the hospitals. The introduction letter was offered to the head nurse of the units, and he/she gave the lists and personal information of the nurses, then, those who had the desired criteria were detected. The researcher took the work schedule of the target subjects and came to them at the time. At first, the researcher described the aims of the study as well as two cases of his experiences of using intuition in clinical practice, while the nurses who have inclusion criteria and a similar experience to use of intuition were identified. In continues, a deep semi-structured interview was conducted to the study participants. Interviewing is synonymous with qualitative research and may become the accepted method of data collection irrespective of methodology. ${ }^{34} \mathrm{~A}$ semi-structured interview is a technique for generating qualitative data and is characterized by openended questions that are developed in advance and by prepared probes. In the semi-structured interview, the interviewer has a set of questions on an interview schedule, but the interview will be guided by the schedule rather than dictated by it; the interviewer is free to probe interesting areas that arise from participants' interests or concerns. ${ }^{25}$ In our study, we used a questionnaire with some open questions such as, What is the definition of intuition?, How do you receive intuition from the patients? and, What are the features of an intuitive nurse in critical care units? and also we applied some other probing questions, for instance where, why and when. The participants were encouraged to talk freely and to tell stories about intuition in clinical practice using their own words. One interview was performed with each participant. At the end of each, the researcher reminded the participants about her need for a second contact with them via telephone calls to discuss the study findings and to make sure that the study findings reflect their own experiences. The duration of each interview was 30 to $60 \mathrm{~min}$. The interviews performed in the critical care units in morning and evening shifts according to the agreement between the researcher and the participants. The sampling process lasted about 6 months from March to August 2015. All the interviews were taperecorded.

\section{Data analysis}

The MAXQDA 10 software (VERBI GmbH, Berlin, Germany) was used for data management, and the data was analyzed as qualitative, through the seven-stage approach of Colaizzi (1978), which the steps represented in the Sanders (2003) and Shosha et al. (2012) studies. $^{35,36}$ The Colaizzi approach is applied to elicit related concepts from the lived experiences of humans and to organize the anecdotal data into phenomenology studies. ${ }^{35}$ In this purpose the following steps were carried out: i) after each interview, we listened to the audio files repeatedly, then the audio file transcribed verbatim, after that the writing files were entered to the MAXQUDA software (VERBI $\mathrm{GmbH}$ ), and read for several times (at least three times); ii) after reading the written interviews, we highlighted the meaningfully related statements; iii) in continue, a concept, which was representative to each statement emerged; iv) after which, the researcher developed the concepts to categories based on their similarity; v) thereafter, the results were incorporated to greater categories; and vi) we tried to offer a comprehensive description to the concepts, eventually; vii) the trustworthiness of the data was accomplished. It is notable the trustworthiness process was commenced along with the data analysis. 
Table 1. Demographic characteristics of the participants.

\begin{tabular}{|c|c|c|c|c|c|c|c|}
\hline Participants & ts Sex & Marital status & Age (year) & Workplace unit & Education & Work history (year) & Work history in critical care (year) \\
\hline P.1 & Male & Married & 31 & ICU & BSC & 9 & 7 \\
\hline P.2 & Female & Single & 32 & ICU & BSC & 11 & 5 \\
\hline P.3 & Male & Married & 37 & ICU & BSC & 10 & 4 \\
\hline P.4 & Male & Single & 30 & ICU & MSC & 9 & 9 \\
\hline P.5 & Female & Single & 34 & ICU & BSC & 10 & 9 \\
\hline P.6 & Male & Married & 42 & ICU & BSC & 18 & 12 \\
\hline P.7 & Female & Married & 38 & ICU & BSC & 15 & 4 \\
\hline P.8 & Female & Single & 48 & ICU & BSC & 30 & 10 \\
\hline P. 9 & Male & Married & 38 & $\mathrm{CCU}$ & MSC & 14 & 14 \\
\hline P.10 & Female & Married & 50 & $\mathrm{CCU}$ & BSC & 22 & 9 \\
\hline P.11 & Female & Married & 28 & $\mathrm{CCU}$ & BSC & 5 & 5 \\
\hline P.12 & Female & Single & 32 & ICU & MSC & 12 & 4 \\
\hline
\end{tabular}

ICU, Intensive Care Unit; BSC, Bachelor of Nursing; MSC, Master Degree; CCU, Cardiac Care Unit.

\section{Trustworthiness}

Rigor was achieved using several strategies included in the trustworthiness criteria consisted of credibility, dependability, conformability and transferability, described by Guba and Lincoln. ${ }^{37,4}$ To enhance credibility, the researchers conducted member checks with participants after the first-level analysis, and again at several points during data analysis. Final member checking occurred as participants were asked to review the findings, comment on the accuracy of interpretations, and confirm descriptions. Credibility was also addressed through peer debriefing; the researchers shared the text summaries, identification of themes, constitutive processes, and final drafts of the findings with the colleagues knowledgeable in nursing and qualitative researches. The participants varied in demographic characteristics such as age, sex, work location, experience in nursing and critical care units and the researcher also believed, in their attitude to the philosophy of qualitative studies, and reciprocal interaction world view, which strengthened the study's credibility. In order to support its dependability, the researcher had prolonged engagement with texts related to the topic, and themes were scrutinized as external checks by experts in psychology, nursing and qualitative approaches. By suspending their prior ideas while extracting themes from the descriptions of the participants, the researchers reinforced the conformability of the study. The researchers believe that transferability of the findings is possible because the sampling was purposive and informational redundancy was achieved. Also, the descriptions were assessed by three expert nurses apart from the study participants, and the results offer enough congruency with their experiences to support transferability.

\section{Results}

Of the 12 nurses who participated in the study, seven (58.3\%) were female and married, and $88.3 \%$ (10 people) had a Bachelor of Nursing, and two had Masters Degrees. The mean and standard deviation of age, job experience and critical care experience were $36.66 \pm 7.01,13.75 \pm 6.82$ and $7.66 \pm 3.36$ years respectively, these rates varied from $28-50$ for age, 5-30 for job experience and 4-14 to critical care experience. Nine of the nurses were working in ICU, and three in CCU (Table 1).

The nurses expressed some similar concepts in response to the open questions such as, How do you receive intuition from the patients? and, What are the features of an intuitive nurse in critical care units?, which were extrapolated into three main themes (proficiency, connection, and benevolence), and ten subthemes (Table 2).

\section{Proficiency}

The nurses represented that they were very proficient in terms of knowledge, skills and experiences. They stated that other colleagues had significant confidence in their work, and could diagnose the clinical situation of patients through a glimpse. Participant (P.) 3 explained, We have complete control and full domination of patient tasks. Some believed these proficiencies lead to the nurses scrutinize the patients holistically. As P.10, who have 22 years work history, remarked it is desire, the nurses do not confine their diagnosis only on the vital signs and shallow symptoms... they must concentrate on patients and receive all the cues.
Table 2. The themes and subthemes of the intuitive nurses in critical care practice.

\begin{tabular}{lc} 
Themes & Subthemes \\
Proficiency & Clinical knowledge \\
& Clinical skill \\
& Clinical experience \\
Connection & Communication \\
& Sympathy \\
& Commitment \\
& Spirituality \\
& Serenity \\
\hline Benevolence & Willing to help \\
& Conscientious \\
\hline
\end{tabular}

\section{Clinical knowledge}

Nearly all the participants mentioned that knowledge of the scientific content of their work was essential for receiving intuitive information. The knowledge should be enough to infer or meet the intuitive voices, as P.3 stated, I fell my knowledge is not very high, however, it is not low too, I think it is a bit greater than others...in my opinion, my mind should not be distracted by that lack (of knowledge). Other nurses also mentioned that to receive the intuitive sense, their brain should not be concerned by scientific issues. In the viewpoint of P.7, the difference between a nurse and a regular person may relate to his/her knowledge that make differ in their viewing angles. She also argued: I must have its scientific backgrounds ...when I feel the track (tracheostomy) of patient will be flawed, I should know what problems might occur with it, maybe it would be closed, or maybe it would be ruptured or a fistula will happen, then they must know the symptoms and treatments of each defect. P.5 also believed intuition and knowledge had strengthening effects on each other and cited 
this is fabulous, if a person has enough knowledge and beside intuition, it could be complement each other..., exactly both, the knowledge and this sense (intuition) can reinforce one another.

\section{Clinical skill}

Seven of the nurses declared clinical skill is an important issue for the intuitive nurses, because it provides a double assurance for nurses applying intuition, and could be considered as the prerequisite for following intuitive voices. After P.6 extracted the tracheostomy of the patient based on his intuition, he said, $I$ was assured in myself to do that work, because if it failed, I could intubate the patient to hold her breathing. Also, P.4 carried out an epinephrine injection to the heart muscle of a fouryear child according to his intuition, because he had the skill to do that procedure without any complications. Five of the participants remarked the intuitive nurse is careful and quick for doing clinical works. In this regard P.12 stated the intuitive nurses are more stringent to perform the clinical duties, they respond to the patient's vital signs variations more time$l y$, report on time, documentation is undertaken accurately, so that the most of the ongoing risks of patients would be prevented by them in a right time. $\mathrm{P.9}$ who has 14 years' experience in CCU and is more intuitive, declared I had more attention to clinical skills since I was a student. One of the nurses announced because nursing student have insufficient clinical skills, they are no intuitive, but the physician students have a night shift, and involve to patients, they take more intuition (P.2).

\section{Clinical experience}

Most of the participants affirmed the role of experience in intuition, and the nurses expressed that they were very experienced in clinical subjects, after dealing with many complicated cases. They declared that the intuitive nurse has reached to an awareness which can infer the patients conditions, even in some cases these inferences are contradicted to the scientific literature and scientific matters, the P. 9 represented sometimes a person reaches to a level of experience that says, what I understand from the patients (is important)... this level is achieved through high working to patients and more experiences, so the nurses are relying upon self for diagnosing the patients problems, not the books and also illustrated, You saw several cases with MI (myocardial infarction) and tachycardia, you did not see a good prognosis about them, and this prevailed to your mind. The experience led to increased confidence in intuition; whenever my experience increases I feel this sense (intuition) more, (P. 2). Some indicated beneficial experience as a real experience, apart from the length of their work history; one nurse stated,
Working in $C C U$ (cardiac care unit) is different to having dexterity in $C C U$ (P.9, P5 and P4). This skill is achieved through engaging in the work and knowing the patients, which was demonstrated by P. 5 . The P4 mentioned a famous Iranian proverb to the value of experience in intuitive nurse, namely the master see something in a raw mud brick, that other does not see in the mirror.

\section{Connection}

Nearly all the participants were interested in being connected and closed to the patients and their environment. They were very positive towards them and believed an intuitive nurse must have strong social relationship skills, and behave in an emotional manner, as the P.2 mentioned, we must change my view and treat to patients with a greater sense. Five sub-themes emerged from these results, including communication, sympathy, commitment, spirituality, and serenity.

\section{Communication}

The intuitive nurses tended to have the best communication with patients, and attempted to do so effectively. The participants commented some verbal and non-verbal communications, these made the patients easily talk about their problems and the nurses earn additional data from patients' status. P.4 understood the patient (a 90-year old man) has many dependencies to his properties from the way of his talking. P.6 mentioned, I constantly speak to my patients even when they are unconscious, even I say to their families to speak to them, because I think they can comprehend my talking through hearing. P.10 announced I myself talk a lot to my patients, I hear their concerns,... they want to be seen, to be heard, to be loved, most of the patients have no anyone to speak, these tasks benefit the therapeutic process, improve their spirit.

The participants indicated some types of known contact including emotional, verbal, eye and deep forms of relationship. P.8 maintained, As I look at them, I feel three or four cues... when I watch by eye, I get more understanding. Furthermore, P.7 expressed, Automatically, a state of dependency was made between me and patients, a special sense that I involuntarily became sensitive to the slightest symptoms of the patients, I have a spiritual awareness of their dependency. Moreover, P.1, 2 and 5 mentioned they had a deep relationship with patients, which led to a fidelity between them. For example, P.1 stated we have more sincerity to my patients, because they remain in my unit for a long time, we face to them every day, however, this may not happens in the general wards.

\section{Sympathy}

Nine of the participants illustrated many sympathetic cues in their treatment of patients, such as compassion, kindness and regarding the patients as members of their families. As P.4 demonstrated about a patient who had undergone to resuscitation I had a pathos sense to the patient, because she had only 4-5 years old. One pointed out, I myself, when a patient is admitted to the ward, I exactly think he/she is my family member... I am pleased when patients go out from here (are discharged) (P.11). Also P. 2 put himself instead of the patients in his mind, to see their conditions from their point of view. P. 4 who cared for an accident 30 years old man, tried to have a twin-concept of patients for the better understanding of them. He said I say, if I was in his place, it is no different, both of us are humans, if this (car accident) happen to me tomorrow, come to ICU, it is no deference, he is 30 years old, I am also thirty, he is in coma, I might get worst,... these senses cause I do twinconcept to patients. P.1 suggested, the nursing student must be educated for having sympathy to patients, he declared the intuition will created accompany to the sense (sympathy).

\section{Commitment}

The nurses felt an obligation to patients and other people, in addition, they struggled to carry out their duties to the best of their abilities and worked overtime. One stated, since I have entered into nursing, I feel responsibilities to others... I have an aid kit in my car for helping the people when they need it, in an event or an accident (P.2). Others represented that nurses must apply themselves beyond the tasks (P.10); furthermore following the patients' conditions (P.3) and having honesty towards patients (P.5). P. 9 pledged himself to convince the family of one patient of the need for special follow up care for him after his discharge. For receiving the intuitive sign, some believed the nurses must have Devotion, this means that the adhering to and fulfilling the patients right is more important than their rights, P.1 stated if that devotion would not create, the intuition is not achieved. P.5 who is working in a general ICU, and her patients is usually unconsciousness, mentioned I try to give a heart to the heart of patients this is an Iranian slang meaning having a deep commitment to comprehend the patients and meeting their needs. Some participants believed, following the intuition their attention and surveillance will be increased, they try to handle patients continually, one of them mentioned if I want to take a tea or pray, I say my colleague to watch the monitor of the 7 bed (the patient rested on the bed of 7), please control it, be careful, that means we constantly go beside the patient and check him/her toward apnea, toward Tachyarrhythmia and so on (P.11). 


\section{Spirituality}

Nearly all the participants attributed their intuition to their relationship to the God. Some described it as an unseen voice which connect the person to the hidden realm, P.10 who had received an inspiration through the intuition toward the patient that would be expired, announced I told, I have an special mystical state, I felt I am connecting to the invisible world, all my counterparts were surprised, they said, the patient is in a good condition... but the next day he dead. other believed because the nurse as well as the patient who have much spiritual power, God provide intuition to help them, for instance P.7 declared if we suppose this is a transcendental sense, it is possible the people who have more humanity receive more intuition to offer a better care.

P.11 implied that the God will be sensed in these medical measures... the nurses and physicians are only a device. Moreover, intuition was considered as a heavenly voice and a mystical state. The nurses believed in numinous spiritual entities and felt their intuitions were inspired by them. P.5 stated, The people who are high-quality in spirituality have more intuition. In addition, five of the nurses represented that their intuitive abilities had been reinforced by praying to God and meditation, as P.5 stated I decided based on my dependencies to undertake a Seclusion (a tradition that some people separate self from other people to be closed to God) and say some verses, after which my intuition has enhanced.

\section{Serenity}

Intuitive nurses were very calm and peaceful towards patients and their colleagues, even in emergency conditions. The informants also represented some factors that disturb the serenity, such as stress, tiredness, high workload and fear of a critical patient, they also could reduce the receiving and acting upon the intuition, one of the nurses believed if we put aside the internal conflicts, the stress, wakeless issue, we offer the best care to patients, but sometimes I know that must do that work (based on my intuition), however I really can't, I have to perform other legal works, for example bringing the patient to the operation room, gavage, mouth washing and so on (P.1). P.9 remarked about the characteristics of intuitive nurses, These nurses are personally quiet, their voices are not loud in the ward... if a problem happens, they undertake very logical actions (are not distressed). P.2 noted that the persons who have a tranquil mind and a healthy psychological state can use intuition easily. Another nurse declared of his colleague that, He is a calm person without any aggression in all situations, even in severe emergencies. In his opinion this serenity affected the process of patients' recoveries (P.6). Some nurses indi- cated to quiet mind as a prerequisite to take intuition cues, one of the nurses (P.4) argued the efficacy of quiet mind is $100 \%$ to intuition, someone who is worried about his/her children, worries about the family, the loans, and commercial matters, obviously his/her thought is not at work purely, so has no attention to intuition.

\section{Benevolence}

According to the participants, intuitive nurses were very benevolent. Most also adhered to humane morals and did the tasks over their duties, as quoted by P.2 they (the intuitive nurses) are self-giving. From these responses, we elicited two sub-themes, conscientious and willingness to help to describe this theme.

\section{Willingness to help}

The nurses declared that they really wanted to help the patients at all times, even when the prognosis was very poor, they remained hopeful and attempted to do everything for patients they could in a compassionate way. The desire to help was an internal feeling, they tried to overcome all the progressive difficulties encountered by the patients; P. 2 stated, I try to hold alive my patient in any possible way... which means you have a great hope, you do any efforts you can, such as, you request a consultation to urologist for checking the infection in urinary system, struggling to lowering the fever and.... P.4 advocated the following about his child patient, When I see a human not have any experience of living, who hasn't gone to school, or achieved any of their wishes, it wasn't interesting for me, so I didn't come short of doing everything I could for him. Some nurses declared this sense (willingness to help) have been fostered from childhood in their family, accordingly P.1 uttered it was induced to me to take the hand of a fallen man by my family, above all, one entity (God) that see all my deeds. Some of the participants such as P.1 and P.5 preferred the patient welfare to their comfort, they declared when the nurses adhere to the nursing criteria such as humanity and honestly help others, could achieve more intuition and reach to the supreme step of humanbeing.

\section{Conscientiousness}

Conscientiousness is noted in all the interviews as a prerequisite to using intuition, in addition, they mentioned an intuitive nurse should act on their conscience, some believed that intuition is equal to having an active conscience. One of the nurses (P.8) advocated the intuition as a positive point, is fostered and intensified by conscientiousness, and P.7 stated that, The people with active consciences are more intuitive... they are very patient and have more close relationships with clients...which is different to those who have little conscientiousness about what happens to the patients. Another nurse (P.5) stated, The individuals with greater conscientious application, not only as a decorative thing, have more humanity and intuition, and could apply it in the therapeutic fields. Some pointed to job conscience as the motivator for performing the right actions, instead of complacency (P.2). Another represented the intuition is a respectful sense like consciousness that guide us to do a good practice (P.1).

\section{Discussion}

Our study was performed in order to better understand the features of an intuitive nurse in critical care practice. Accordingly, the results showed such nurses mostly had high proficiency in terms of clinical knowledge, skill and experience. Additional to job experience, Ruth Sahad and Tisdell (2007) remarked that life experiences such as having a case of death or serious patients in nurses' families was a contributing factor to nurses' intuition. ${ }^{7}$ In Kosowski and Roberts' study, the participants spoke about the importance of having an accurate and substantive knowledge of contextual variables because acting on their intuition felt like taking a risk, and agreed that comprehensive knowledge of the agency's system and its adherence to protocols was a key factor in their ability to use intuition in clinical decision making. ${ }^{4}$ Miller (1995), also mentioned clinical mastery to describe an intuitive nurse. ${ }^{2}$ The results of Lyneham et al. (2008) confirmed that expertise in intuitive nurses would be achieved through three phases; cognitive intuition, where assessment is processed subconsciously and can be rationalized in hindsight; transitional intuition, where a physical sensation and other behaviors enter the nurse's awareness; and embodied intuition, when the nurse trusts the intuitive thoughts. ${ }^{12}$ However, in the opinion of Pretz and Folse, the experience has effect on just some special parts of intuition, such as skillful domain, even though there are no correlations between them in terms of physical and spiritual extents. ${ }^{14}$ Smith et al. (2004) and Ericsson et al. (2007), illustrated that experience is not equivalent to expertise and that intuition in registered nurses is similar to nursing students. ${ }^{6,38}$

It appears that with all nurses, including nursing students comprehending intuition, having clinical knowledge and experience boosts the use of intuition. In other words, with increasing experience of it, nurses aware of the value of intuition rely on it more. This indicates a need for further studies.

The findings revealed that intuitive nurses have better relationships and more connec- 
tions with patients and spiritual entities. In accordance with our study, the nurses in Ruth Sahad and Tisdell's study (2007), claimed connection is the central meaning of intuition, which they attributed to connection to spiritual sources such as God, connection to the trust of their colleagues and connection to patients. ${ }^{7}$ Smith (2006) elicited three factors namely, spiritual connections, reading cues and sensing energy in her instrument for describing the intuitive student nurses. These factors were explained through statements such as, I experience a deep connection with my patients, I read nonverbal cues of my patient, and I sense an energy field around my patient. Other researchers concluded the relationship between nurse and patient has a synergic effect on the development of intuition in nurses and interacts with other variables such as knowledge, experience, expertise, personality, environment, and accepting the validity of intuition. ${ }^{5}$

It is believed that Intuition is informationbased, meaning for creating it one must receive data from the environment, ${ }^{39}$ Some scientists remarked the humans can receive information through energy fields as a person to person, person to location and person to the future. ${ }^{40}$ This energy could be positive or negative, the positive energy originated from some behaviors such as having compassionate, empathy, sympathy, help to other, and appreciation. These associated to the human heart and emotions, thus, the individuals who have more relationship could catch more information from the energy fields, ${ }^{41,42}$ hence, due to the high effects of verbal and nonverbal communications on patient care and healing processes, ${ }^{43,44}$ we believe the connection may have a crucial role in establishing the value of intuition in nursing.

We found that desire to help and being conscientious are fundamental features of intuitive nurses working in the critical care arena. However, we could not find any research on these features in the literature. While some authors asserted that conscience is the internal sense of moral goodness or badness of the conduct of oneself or others. ${ }^{45}$ The moral intuitions, which are the feelings that some acts are right and others are wrong, are the products of conscience. In addition, when nurses are asked to narrate the moral challenges in patient care situations, they mostly refer to their conscience. ${ }^{46}$ Intuition also has a significant role in recognizing the most ethical nursing measures, ${ }^{47}$ which implies similarities between two features. The workplace culture could also alter nurses' understanding of intuition, ${ }^{48}$ thus providing an argument for, further studies into cultural backgrounds.

\section{Conclusions}

This study investigated the features of critical care practice in intuitive nurses. In this regard three main themes (proficiency, connection and benevolence) and ten sub-themes emerged. The results revealed that intuitive nurses have multiple proficiencies in clinical knowledge, skill and experience. They are very peaceful and want to be connected to the patients and spiritual entities. They adhere to moral issues, desire to help more, and refer more to their consciences when undertaking patients' care.

\section{Limitations}

The participants were nurses who had experienced intuition in clinical practice, and who enrolled in a purposive study. However, the use of semi-structured questioning would restrict the free expressions of lived experiences and their meaning, and as qualitative research, these results could not be generalized to other locations. Hence, other qualitative studies in various clinical settings are recommended.

\section{References}

1. Miller VG. Measurement of self-perception of intuitiveness. West J Nurs Res 1993;15: 595-606.

2. Miller VG. Characteristics of intuitive nurses. West J Nurs Res 1995;17:305-16.

3. Lyneham J, Parkinson C, Denholm C. Intuition in emergency nursing: a phenomenological study. Int $\mathrm{J}$ Nurs Pract 2008;14:101-8.

4. Kosowski MM, Roberts VW. When protocols are not enough. Intuitive decision making by novice nurse practitioners. $\mathrm{J}$ Holist Nurs 2003;21:52-72.

5. McCutcheon HH, Pincombe J. Intuition: an important tool in the practice of nursing. $\mathrm{J}$ Adv Nurs 2001;35:342-8.

6. Smith AJ, Thurkettle MA, la Cruz FA. Use of intuition by nursing students: instrument development and testing. J Adv Nurs 2004;47:614-22.

7. Ruth-Sahd LA, Tisdell EJ. The meaning and use of intuition in novice nurses: A phenomenological study. Adult Educ Quarterly 2007;57:115-40.

8. Rovithis M, Parissopoulos S. Intuition in nursing practice. ICUS Nurs Web J 2005;22:1-10.

9. Chaffey L, Unsworth CA, Fossey E. Relationship between intuition and emotional intelligence in occupational thera- pists in mental health practice. Am $\mathrm{J}$ Occup Ther 2012;66:88-96.

10. Pearson H. Science and intuition: do both have a place in clinical decision making? Br J Nurs 2013;22:212-5.

11. Green C. Nursing intuition: a valid form of knowledge. Nurs Philos 2012;13:98-111.

12. Lyneham J, Parkinson C, Denholm C. Explicating Benner's concept of expert practice: intuition in emergency nursing. $\mathrm{J}$ Adv Nurs 2008;64:380-7.

13. Benner P, Tanner C. How expert nurses use intuition. AJN Am J Nurs 1987;87:2334.

14. Pretz JE, Folse VN. Nursing experience and preference for intuition in decision making. J Clin Nurs 2011;20:2878-89.

15. Cork LL. Nursing intuition as an assessment tool in predicting severity of injury in trauma patients. J Trauma Nurs 2014;21:244-52.

16. Pretz JE, Brookings JB, Carlson LA, et al. Development and validation of a new measure of intuition: the types of intuition scale. J Behav Decision Making 2014;27:454-67.

17. Ramezani-Badr F, Nasrabadi AN, Yekta ZP, Taleghani F. Strategies and criteria for clinical decision making in critical care nurses: a qualitative study. J Nurs Scholar 2009;41:351-8.

18. Valiee S, Negarandeh R, Hghan Nayeri N. Exploration of Iranian intensive care nurses' experience of end of life care: a qualitative study. Nurs Crit Care 2012;17:30915.

19. Hams SP. A gut feeling? Intuition and critical care nursing. Intens Crit Care Nurs 2000;16:310-8.

20. Smith A. Exploring the legitimacy of intuition as a form of nursing knowledge. Nurs Standard 2009;23:35-40.

21. Ruth-Sahd LA. What lies within: phenomenology and intuitive self-knowledge. Creative Nurs 2014;20:21-9.

22. Gina M. Understanding the differences between Husserls (descriptive) and Heidegger's (interpretive) phenomenological research. J Nurs Care 2012;5:1-3

23. Groenewald T. A phenomenological research design illustrated. Int J Qual Methods 2004;4:1-25.

24. Rafique R, Hunt N. Experiences and coping behaviours of adolescents in Pakistan with alopecia areata: an interpretative phenomenological analysis. Int J Qual Stud Health Well-being 2015;10:1-13

25. Chan ZC, Fung YL, Chien WT. Bracketing in phenomenology: only undertaken in the data collection and analysis process. Qual Rep 2013;18:1-9. 
26. Lopez KA, Willis DG. Descriptive versus interpretive phenomenology: their contributions to nursing knowledge. Qual Health Res 2004;14:726-35.

27. Meskarpour-Amiri M, Mehdizadeh P, Barouni M, et al. Assessment the trend of inequality in the distribution of intensive care beds in iran: using GINI index. Global J Health Sci 2014;6:28-36.

28. Zhou L, Tao Z, Wu Y, et al. Individual and institutional factors affecting cardiac monitoring in coronary care units: a national survey of Chinese nurses. Int $\mathbf{J}$ Nurs Stud 2012;49:570-8.

29. Sandelowski M. Focus on research methods-whatever happened to qualitative description? Res Nurs Health 2000;23:33440.

30. Walker JL. The use of saturation in qualitative research. Can J Cardiovasc Nurs 2012;22:37-46.

31. Bowen GA. Naturalistic inquiry and the saturation concept: a research note. Qual Res 2008;8:137-52.

32. Guest G, Bunce A, Johnson L. How many interviews are enough? An experiment with data saturation and variability. Field Methods 2006;18:59-82.

33. Nixon A, Wild D. Methodologies for assessing and demonstrating data saturation in
Qualitative inquiry supporting patientreported outcomes research. Value Health 2008;11:A569.

34. Wimpenny P, Gass J. Interviewing in phenomenology and grounded theory: is there a difference? J Adv Nurs 2000;31:1485-92.

35. Shosha GA. Employment of Colaizzi's strategy in descriptive phenomenology: a reflection of a researcher. Eur Sci J 2012;8:31-43.

36. Sanders C. Application of Colaizzi method: Interpretation of an auditable decision trail by a novice researcher. Contemp Nurse 2003;14:292-302.

37. Schwandt TA, Lincoln YS, Guba EG. Judging interpretations: but is it rigorous? trustworthiness and authenticity in naturalistic evaluation. New Direct Eval 2007;2007:11-25.

38. Ericsson KA, Whyte IV J, Ward P. Expert performance in nursing: reviewing research on expertise in nursing within the framework of the expert performance approach. Adv Nurs Sci 2007;30:E58-E71.

39. Effken JA. Informational basis for expert intuition. J Adv Nurs 2001;34:246-55.

40. Radin DI. Unconscious perception of future emotions: an experiment in presentiment. J Sci Explor 1997;11:163-80.

41. Dargahi H. Quantum leadership: the impli- cation for Iranian nursing leaders. Acta Med Iranica 2013;51:411-7.

42. Shelton CD, Darling JR, Walker WE. Foundations of organizational excellence: leadership values, strategies, and skills. Finnish J Business Econ 2002;1:46-63.

43. Stewart MA. Effective physician-patient communication and health outcomes: a review. CMAJ Can Med Assoc J 1995;152:1423.

44. Epstein R, Street R Jr. Patient-centered communication in cancer care: promoting healing and reducing suffering. Bethesda, MD: National Cancer Institute; 2007. NIH publication 07-6225.

45. Thagard P, Finn T. Conscience: What is moral intuition. Moral Emot 2011;150-69.

46. Jalali R, Hasani P, Abedsaeedi Z. Nurses' experience of the perception of nursing conscience: a phenomenological study. Asian Bioethics Rev 2012;4:210-25.

47. Sofaer B. Enhancing humanistic skills: an experiential approach to learning about ethical issues in health care. J Med Ethics 1995;21:31-4.

48. Demir Y, Denat Y, Khorshid L, Eser I. Cultural validation of the use of intuition by nursing students scale - Turkish version. J Transcult Nurs 2012;23:369-76. 